\title{
The key to costal cartilage in rhinoplasty
}

\author{
Hong Ryul Jin \\ Dr. Jin's Premium Nose Clinic, Seoul 06524, South Korea. \\ Correspondence to: Dr. Hong Ryul Jin, MD PhD, Dr. Jin's Premium Nose Clinic, Seoul 06524, South Korea. \\ E-mail:doctorjin@daum.net
}

How to cite this article: Jin HR. The key to costal cartilage in rhinoplasty. Plast Aesthet Res 2019;6:19. http://dx.doi.org/10.20517/2347-9264.2019.28

Received: 6 Jun 2019 Accepted: 4 Jul 2019 Published: 9 Aug 2019

Science Editor: Raúl González-García Copy Editor: Jia-Jia Meng Production Editor: Jing Yu

Keywords: Costal cartilage, rhinoplasty, harvesting, carving, application, complication

Autologous costal cartilage is an excellent source of graft in rhinoplasty due to its rich supply, durability, versatility, and functionality. For a long time, rhinoplasty surgeons have been critical of using autologous costal cartilage based on the potential for associated complications including donor site morbidities, postoperative pain, warping, and long operation time.

Even with this criticism, costal cartilage is still a graft material of choice in cartilage depleting revision rhinoplasty. Recently, there has been a steady increase in costal cartilage use even in primary augmentation rhinoplasty, especially in Asian. This is attributed to the increased awareness of alloplast-associated complications and continuously developed techniques to minimize potential complications and maximize the benefits of costal cartilage.

In this special issue, world-renowned rhinoplasty experts discuss a variety of aspects of costal cartilage use in rhinoplasty. These include preoperative considerations, harvesting and carving techniques, diverse clinical applications, and management of complications in costal cartilage use. As veterans in the field of rhinoplasty, these experts share in great detail invaluable knowledge that can only be attained through extensive clinical experience and continuous effort toward innovation and mastery of their craft.

First, a national survey of current trends in costal cartilage use in rhinoplasty by Clara M. Olcott and Steve J. Pearlman will give us a glimpse of the common practice patterns of using costal cartilage in US facial plastic surgeons. Preoperative considerations focus on determining the availability of the costal cartilage and the site of harvesting. Costal cartilage calcification is not infrequent even in young patients

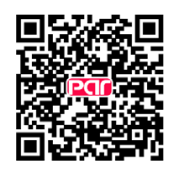


and size, shape, and length of straight cartilaginous portion differs greatly from patient to patient. Tips on evaluating and analyzing preoperatively and postoperative care considerations delivered by Jong-Sook Yi will be of great help to the beginning rhinoplasty surgeons.

Recent advances in harvesting techniques focus on the minimal incision and minimal pain. Most surgeons use $3.0 \mathrm{~cm}$ or more incision considering the depth of dissection and the size of harvesting cartilage. Minimizing the size of the incision in harvesting was pioneered by Dean Toriumi and he reduced incision size up to $1 \mathrm{~cm}$. Although it is fascinating, it needs experience, skill, and patience, and it is not for all rhinoplasty surgeons. As an alternative, an endoscope harvesting technique by Abdulkadir Goksel also helps to minimize scar and pain.

Reducing the chest pain after harvesting was facilitated by several technical modifications: keeping the underlying perichondrium intact, dissecting and retracting the covering muscles instead of cutting, and harvesting cartilage partially leaving a thin layer of cartilage at the superior and inferior margins. Experts will elaborate in great detail their techniques in terms of reducing postoperative pain.

The carving technique of costal cartilage was the main concern for rhinoplasty surgeons. Warping has been the most criticized point, and the chances increase even more when using the rib for major dorsal augmentation, which is quite common in Asian. A few key techniques to prevent warping including the oblique splitting method by Fazil Apaydin has been introduced in this issue. I hope readers can modify their techniques according to their situation by referring to these articles. Diced cartilage wrapped in temporalis fascia has been popularized by Rollin Daniel. It has been introduced as a solution for warping and its use is slowly increasing. Techniques to avoid drawbacks of dicing method are introduced by young, talented surgeon Donald Yoo.

The final aspect of using costal cartilage is an application of the above-mentioned techniques in diverse patients. Septal application includes splinting, replacement, extension, and spreader grafts. Dorsum and tip applications include augmentation, reinforcement, camouflage, onlay, and strut grafts. Each application has points to be addressed and these are also covered in many case series with illustrative patient photos by Tae-Bin Won and Chuan-Hsiang Kao.

I am confident that this special issue will provide meaningful insight into the diverse aspects of using costal cartilage in rhinoplasty. It is my sincere hope that readers will be able to enhance their skills and integrate this cutting-edge knowledge into their practice to provide patients with the best experience possible.

\section{DECLARATIONS}

\section{Authors' contributions}

The author contributed solely to the article.

\section{Availability of data and materials}

Not applicable.

\section{Financial support and sponsorship}

None.

\section{Conflicts of interest}

The author declared that there are no conflicts of interest. 
Jin. Plast Aesthet Res 2019;6:19 I http://dx.doi.org/10.20517/2347-9264.2019.28

Ethical approval and consent to participate

Not applicable.

\section{Consent for publication}

Not applicable.

\section{Copyright}

(c) The Author(s) 2019. 